\title{
KINERJA PERALATAN BONGKAR GENERAL CARGO (STEEL BILLET) PADA MV. HARMONY SW OLEH PT BINTANG MUSTIKA SAKTI DI PELABUHAN CIWANDAN BANTEN
}

\author{
Himawan Aditya Pratama ${ }^{1 *}$, Siska Nur ${ }^{2}$ \\ ${ }^{1}$ Program studi Transportasi, Sekolah Tinggi Maritim Yogyakarta, \\ Jl. Magelang Km 4.4, Sinduadi, Mlati, Sleman, Yogyakarta. \\ ${ }^{2}$ Program studi Manajemen Transportasi Laut, Sekolah Tinggi Maritim Yogyakarta \\ Jl. Magelang Km 4.4, Sinduadi, Mlati, Sleman, Yogyakarta. \\ "Email: himawan.aditya.pratama@gmail.com
}

\begin{abstract}
Abstrak
Semakin berkembangnya teknologi bongkar muat menuntut pelabuhan dalam meningkatkan kualitas peran dan fungsinya sebagai terminal point bagi barang dan kapal. Untuk menunjang kelancaran pelayanan proses bongkar muatan, tentu saja memerlukan peralatan bongkar muat yang layak digunakan baik peralatan mekanis maupun non-mekanis. Permasalahan yang dihadapi dalam proses bongkar muat pada MV. Harmony SW. yaitu : bagaimana pengaruh kinerja peralatan bongkar muat terhadap kelancaran proses bongkar muat dan upaya - upaya yang perlu dilakukan untuk mengoptimalkan penggunaan peralatan bongkar muat. Sesuai dengan permasalahan yang dihadapi dalam mengoptimalkan kinerja peralatan muncul jawaban sementara atas masalah yang dikemukakan, diantaranya diduga bahwa penyebab proses bongkar muat bisa menjadi lama karena butuh kehati-hatian dalam pemasangan sling ware dan dalam kurangnya perawatan alat bongkar muat sehingga menjadi menghambat proses bongkar muat. Metode yang digunakan : jenis data primer dan sekunder, metode pengumpulan data menggunakan observasi, interview dan dokumentasi.
\end{abstract}

Kata kunci: Bongkar, Kinerja,Peralatan.

\section{PENDAHULUAN}

Pelabuhan adalah tempat yang terdiri dari daratan dan perairan disekitarnya dengan batas-batas tertentu sebagai tempat kegiatan pemerintahan dan kegiatan ekonomi yang dipergunakan sebagai tempat kapal bersandar, berlabuh, naik turun penumpang dan / atau bongkar muat barang yang dilengkapi dengan fasilitas keselamatan pelayaran dan kegiatan penunjang pelabuhan serta sebagai tempat perpindahan intra dan antar moda transportasi. (indomaritim.id, 2020)

Dengan semakin berkembangnya lalu lintas angkutan laut, teknologi bongkar muat, meningkatnya perdagangan antar pulau dan perdagangan internasional, hal ini menuntut pelabuhan dalam meningkatkan kualitas peran dan fungsinya sebagai terminal point bagi barang dan kapal. Oleh karena itu, setiap negara berusaha membangun dan mengembangkan pelabuhannya sesuai dengan tingkat keramaian dan jenis perdagangan yang ditampung oleh pelabuhan tersebut. (R.P.Suyono, 2007)
Untuk menunjang kelancaran pelayanan proses bongkar muatan, tentu saja memerlukan peralatan bongkar muat yang layak digunakan baik peralatan mekanis maupun non-mekanis. Apabila pengerjaan dilakukan dengan waktu yang semakin lama maka biaya yang akan dikeluarkan semakin banyak dan jika waktu pengerjaan dilakukan dengan cepat maka biaya yang dikeluarkan akan semakin sedikit sehingga keuntungan pun menjadi semakin besar. (R. P. Suyono, 2007)

PT. Bintang Mustika Sakti merupakan perusahaan bongkar muat yang berada di Pelabuhan Ciwandan Banten. Perusahaan tersebut menangani proses bongkar muatan steel billet pada kapal MV Harmony SW. Adapun permasalahan yang dihadapi Pada pelaksanaan kegiatan bongkar muatan steel billet di MV.Harmony SW, seperti alat-alat bongkar muat yang rusak, terjadinya waiting truck yang mengakibatkan keterlambatan dalam proses pengangkutan barang, sehingga menghambat kegiatan bongkar di pelabuhan. 
Untuk meminimalisir hambatan tersebut maka perlu adanya tingkat kinerja yang baik pada saat pelaksanaan kegiatan bongkar steel billet pada kapal MV.Harmony SW.

\section{LANDASAN TEORI \\ Operasi Bongkar Muat}

Menurut Suyono (2007), pada kegiatan bongkar muat meliputi banyak bagian dalam suatu proses bongkar ataupun muat. Jasa bongkar muat di pelabuhan dilakukan oleh pihak Perusahaan Bongkar Muat. Perusahaan bongkar muat (PBM) adalah badan hukum Indonesia yang khusus didirikan untuk menyelenggarakan dan mengusahakan kegiatan bongkar muat dari dan ke kapal.

\section{Sebelum kapal tiba}

Menurut Suyono (2007), beberapa hari sebelum kapal tiba, para petugas yang akan melaksanakan bongkar muat akan memeriksa dan mengelola data yang diterima, menyangkut kapal dan muatan yang akan dikerjakan. Kemudian mereka akan melakukan pertemuan yang sering disebut dengan pre-arrival meeting (PAM). Di dalam pertemuan ini disusun rencana kerja berdasarkan data yang ada.

Setelah data/informasi diolah, langkah selanjutnya adalah melakukan persiapan sebagai berikut:

a) Menunjuk petugas survisor, yang terdiri dari : stevedore, chief tally clerk, foreman, tally clerk, mistri, watchman yang akan mengerjakan kapal.

b) Rapat koordinasi antar mereka tantang tugas dan penanggungan serta perkiraan keberangkatan kapal dan penundaan yang mungkin akan terjadi.

c) Pembicaraan dengan agen atau principal dan pemilik barang untuk memperlancar pelaksanaan tugas.

d) Koordinasi dengan petugas pelabuhan dan bea-cukai.

Hasil dari rapat koordinasi dan pembicaraan akan menghasilkan tindakan berupa :

a) Persiapan operasi

b) Permintaan buruh

c) Persiapan peralatan mekanis/non- mekanis

d) Konsentrasi perlengkapan petugas stevedore, foreman dan buruh berupa sarung tangan, masker, dan lain-lain.

e) Pemberitahuan kepada pergudangan, petugas krani, surveyor, kemanan serta petugas lain yang diperlukan.

\section{Sesudah kapal tiba}

Persiapan membuka palka kapal. Bila palka kapal sudah dibuka, perwira kapal dengan surveyor akan masuk untuk memeriksa keadaan muatan guna mengetahui apakah ada keringat atau rusak dan dicatat seperlunya

\section{Kegiatan Bongkar di Kapal}

Ship operation adalah kegiatan bongkar/muat dikapal yang mempergunakan perlatan bongkat/muat kapal atau juga dinakaman boom atau derek. Operasi dari derek terdiri dari 4 langkah yaitu :

a) Mengaitkan sling wire dan ganco atau hook pada muatan dalam palka.

b) Memindahkan ganco berisi muatan dari palka ke dermaga di sisi kapal.

c) Melepaskan sline wire di muatan dari ganco ke dermaga, muatan diletakkan di atas dermaga.

d) Mengembalikan ganco dari dermaga ke palka, untuk melanjutkan kegiatan berikut.

Langkah a,b,c,d dinamakan hookcycle atau hookcycle time (satu siklus). Satuan dasar untuk mengukur siklus ini adalah satu jam. Rumusnya :

$$
\frac{60}{\text { hook cyle time }}
$$

Jadi, bila waktu siklus adalah 5 menit maka dalam satu jam terdapat 12 siklus.

\section{Cargodoring}

Cargodoring adalah pekerjaan memindahkan barang dari dermaga ke gudang atau tempat penumpukan. Dalam pelaksanaannya, produktivitas cargodoring dipengaruhi oleh tiga variabel yaitu jarak 
tempuh, kecepatan kendaraan dan waktu tidak aktif.

1) Jarak tempuh

2) Kecepatan kendaraan

3) Waktu tidak aktif

4) $\mathrm{v}=\frac{s}{t}$

Keterangan :

$\mathrm{t}=$ Waktu tempuh (jam,second)

$\mathrm{s}=$ Jarak tempuh $(\mathrm{m}, \mathrm{km})$

$\mathrm{v}=\operatorname{Kecepatan}(\mathrm{km} / \mathrm{jam}, \mathrm{m} / \mathrm{s})$

\section{Receiving/Delivery}

Operasi penerimaan/penyerahan muatan merupakan kegiatan penerima atau menyerahkan barang dari dan ke wilayah pelabuhan. Kegiatan receiving/delivery pada dasarnya ada dua macam, yaitu, pola angkutan langsung dan pola angkutan tidak langsung.

\section{METODE}

Menurut Mardalis (2010) Metodologi penelitian dibutuhkan sebagai langkah pembekalan pengetahuan tentang arti dari penelitian, langkah-langkah penelitian serta konseptualisasi penelitian dalam praktik kerja di lapangan. Metodologi penelitian juga membantu penyusun untuk memiliki keterampilan dalam melakukan penelitian di tempat praktik kerja dan dalam penyusunan laporan praktik kerja dengan memperhatikan etika-etika yang ada, seperti:

\section{Jenis dan Sumber Data}

Menurut Sugiyono (2015) Jenis dan sumber data penelitian dibedakan menjadi 2, yaitu sumber data primer dan sumber data sekunder.

\section{a. Data Primer}

Data primer yang digunakan adalah data yang diperoleh secara langsung di lapangan baik berupa foto dan pengamatan. Metode wawancara mendalam atau in-dept interview dilakukan kepada beberapa target wawancara yaitu 1. Bagian operasional, 2. Bagian K3 dan 3. TKBM yang melaksanakan bongkar muat di $M V$.Harmony.SW data tersebut dipergunakan untuk memperkuat hasil pengamatan dan data.

\section{b. Data Sekunder}

Data sekunder yang digunakan adalah data yang berasal dari dokumen terkait proses bongkat muat di MV.Harmony SW. Baik dari laporan, tabel, grafik, dan statistik jumlah muatan, waktu yang dibutuhkan dan jumlah tkbm yang melakukan proses bongkar.

\section{Metode Pengumpulan Data}

Adapun metode pengumpulan data dapat dilakukan dengan :

\section{a. Metode Observasi}

Obsevasi atau pengamatan digunakan dalam rangka mengumpulkan data dalam suatu penelitian, merupakan hasil perbuatan jiwa secara aktif dan penuh perhatian untuk menyadari adanya suatu rangsangan tertentu yang diinginkan, atau studi yang disengaja psikis dengan jalan mengamati atau mencatat. (Mardalis, 2010)

\section{b. Metode Interview (Wawancara)}

Wawancara adalah teknik pengumpulan data yang digunakan peneliti untuk mendapatkan keterangan-keterangan lisan melalui bercakap-cakap dan berhadapan muka dengan orang yang memberikan keterangan pada si peneliti. (Mardalis, 2010)

\section{c. Metode Dokumentasi}

Dokumentasi adalah pengumpulan data yang sudah dilakukan oleh pihak lain ataupun yang ada pada perusahaan atau instansi terkait, media masa yang ada hubungannya dengan masalah judul dari peneliti (Mardaslis, 2010)

\section{HASIL DAN PEMBAHASAN}

Pada pembahasan ini menurut hasil wawancara penyusun dengan pihak operasional PBM PT Bintang Mustika, kapal-kapal dengan muatan steel billet paling sering menggunakan jasa perusahaan bongkar muat ini untuk melakukan kegiatan pembongkaran.

Kapal-kapal besar ini biasanya mengangkut muatan steel billet sebanyak kurang lebih 2.000 pcs sampai lebih dari 11.000 pcs steel billet. Lama pengerjaannya pun juga tergantung dari berapa banyak muatan yang 
akan dibongkar dan ada atau tidaknya kendala-kendala lain yang akan mempengaruhi proses pembongkaran seperti gelombang tinggi, cuaca buruk, alat rusak dan lain sebagainya.

Kapal Harmony SW merupakan kapal berbendera Panama dengan nomor voyage 130 berasal dari Pelabuhan Kemaman Malaysia, yang melalui pemilik barang yaitu PT Krakatau Osaka Steel menunjuk PT Puninar Jaya sebagai perusahaan trucking dan Perusahaan Bongkar Muat PT Bintang Mustika Sakti untuk menangani kegiatan pembongkaran steel billet di Pelabuhan Ciwandan, dan mengangkut muatan (cargo) steel billet dari dermaga ke gudang penumpukan di PT Krakatau Osaka Steel.

Standar pelaksanaan kegiatan bongkar steel billet pada MV Harmony SW dengan jumlah muatan 4.823 pcs adalah berlangsung kirakira selama kurang lebih 4 hari, tergantung juga dengan ada atau tidaknya kendala pada saat pengerjaan, seperti cuaca buruk, gelombang tinggi atau rusaknya alat pada saat melakukan pembongkaran.

Adapun alur yang dilakukan oleh PT Bintang Mustika Sakti pada pelaksanaan kegiatan bongkar general cargo (steel billet) sebagai berikut :

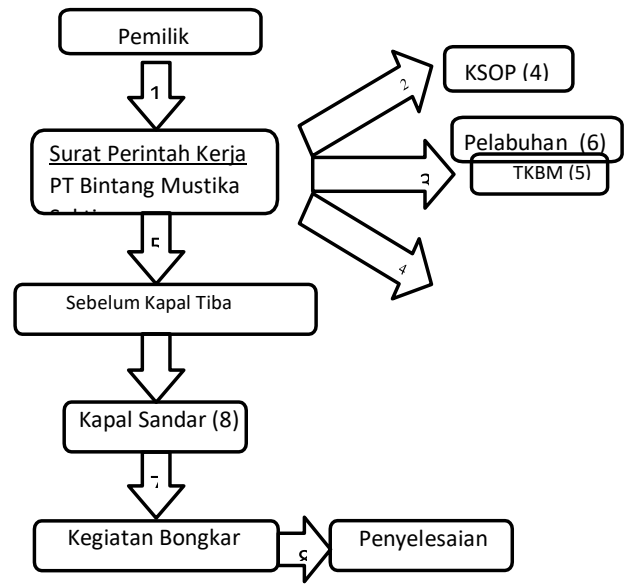

Sumber : Diolah Penyusun 2020

\section{Perhitungan Kinerja Peralatan Bongkar Steel Billet}

Sistem kerja pada PT Bintang Mustika Sakti terbagi menjadi 3 shift untuk setiap shift yaitu 8 jam kerja yang sudah termasuk 1 jam untuk waktu istirahat, shift kerja yang dimuat adalah shift $\mathrm{I}=06.00-14.00$, shift II $=14.00-22.00$, dan shift III $=22.00-06.00$.
Berikut adalah sistem perhitungan kinerja peralatan bongkar steel billet pada MV Harmony SW yang dimulai pada tanggal 10 Maret 2020 yang dilakukan oleh PT Bintang Mustika Sakti di Pelabuhan CiwandanBanten :

\section{1) Ship's Crane}

Kapal MV Harmony yang sandar di Pelabuhan Ciwandan Banten pada tanggal 10 Maret 2020 pukul 21.35 kemudian memulai kegiatan bongkar pada tanggal 11 Maret 2020 pada pukul 01.55 dini hari yang terdapat dalam time sheet 1 (Lampiran 12). Berdasarkan cargo manifest MV Harmony SW membawa muatan yang akan dibongkar di Pelabuhan Ciwandan sebanyak 4.823 pieces.

Alat yang digunakan untuk memindahkan atau mengangkat muatan steel billet dari dalam palka MV Harmony SW ke dermaga adalah menggunakan ship crane. Dengan langkah kerja ship crane antara lain sebagai berikut :

a) Di dalam palka, sling wire yang terletak di kedua sisi steel billet masing-masing dikaitkan pada ganco untuk mengunci muatan yang akan diangkut.

b) Operator crane menggerakkan crane berisi muatan dari dalam palka ke atas dermaga.

c) Melepaskan sling wire pada kedua sisi muatan steel billet.

d) Operator crane mengembalikan lagi ke dalam palka untuk mengangkat muatan yang berikutnya.

Dari langkah a, b, c dan d di atas, terjadilah satu siklus pengangkatan muatan 5 pcs, PT Bintang Mustika Sakti rata-rata satu siklus membutuhkan waktu sekitar 5 menit. Jadi jumlah muatan yang terbongkar dalam satu jam dengan setiap waktu siklus selama 5 menit, dengan rumus perhitungan sebagai berikut :

Banyaknya Muatan Terbongkar Dalam $1 \mathrm{jam}=\frac{60 \text { menit }}{\text { waktu satu siklus }} \times$ muatan

Banyaknya muatan Terbongkar Dalam 1 $\mathrm{jam}=\frac{60 \text { menit }}{5 \text { menit }} \times 5$ pcs $=60 \mathrm{pcs}$ 
Jadi muatan steel billet yang terbongkar dalam waktu 1 jam apabila satu siklus memakan waktu 5 menit adalah sebanyak 60 pcs steel billet. Akan tetapi dalam waktu 1 jam sebanyak 60 pcs tersebut pada kenyataannya di lapangan yang penyusun temukan bisa kurang atau juga bisa lebih karena ada beberapa faktor seperti :

a. Pengangkatan muatan terkadang lebih atau kurang dari 5 pcs.

$b$. Kurang cekatannya buruh TKBM dalam mengaitkan dan melepaskan sling wire pada ganco.

c. Gelombang yang cukup tinggi sehingga menyebabkan pergerakan crane tidak stabil pada saat pengangkatan atau pada saat penurunan di dermaga.

d. Posisi muatan yang tidak pas untuk pemasangan sling wire sehingga memperlambat proses pengangkatan, ataupun sebaliknya.

e. Perlunya waktu tambahan untuk mengangkat forklift dari dermaga ke dalam palka untuk membantu proses pengambilan muatan yang tidak terjangkau oleh ship's crane.

Kegiatan pembongkaran MV. Harmony SW yang dimulai pada tangga 11 Maret 2020 pada pukul 01.55 dan selesai melakukan pembongkaran pada tanggal 14 Maret 2020 pada pukul 01.00 seperti yang terlampir dalam time sheet dengan jumlah muatan yang berhasil dibongkar sebanyak 4.823 pieces dengan rincian seperti yang tertera di daily working time dan statement of fact. Perincian berdasarkan statement of fact jumlah yang dibongkar pada shift 1, 2, 3 dan 4 adalah sebagai berikut :

Tabel 1. Laporan Hasil Bongkar

\begin{tabular}{|l|c|c|c|}
\hline \multicolumn{1}{|c|}{ HARI } & TANGGAL & JAM & $\begin{array}{c}\text { TOTAL } \\
\text { DISCHARGE }\end{array}$ \\
\hline Hari I & 10-11 Maret 2020 & $01.00-07.00$ & 200 \\
\hline Hari II & 11-12 Maret 2020 & $07.00-07.00$ & 1675 \\
\hline Hari III & 12-13 Maret 2020 & $07.00-07.00$ & 1475 \\
\hline Hari IV & 13-14 Maret 2020 & $07.00-07.00$ & 1473 \\
\hline
\end{tabular}

Sumber : Diolah Penyusun

\section{2) Forklift}

Jumlah forklift yang digunakan dalam pembongkaran steel billet pada MV. Harmony SW ini adalah sebanyak 2 forklift dengan kapasitas masing-masing 20 ton.

Menurut hasil pengamatan penyusun di lapangan, pada saat memindahkan steel billet dari dermaga ke atas truk, forklift dapat mengangkat 5 pcs steel billet dan membutuhkan waktu kurang lebih 2 menit. Jadi jika untuk mengangkat 5 pcs steel billet membutuhkan waktu 2 menit, maka dalam satu jam forklift bisa mangangkat muatan steel billet dari dermaga ke atas truk sebanyak 150 pcs.

Dari hasil perhitungan penyusun, dalam waktu satu jam jumlah muatan yang berhasil diaangkut mulai dari pengoperasian ship's crane untuk mengambil muatan di dalam palka dan menurunkannya di dermaga, kemudian forklift mengambil muatan di dermaga dan mengangkatnya ke atas truk adalah kurang lebih sebanyak 80 pcs steel billet.

\section{3) Truck Pengangkut}

Sebagai bahan kajian, meskipun kegiatan cargodoring ini tidak ditangani oleh PT Bintang Mustika Sakti, namun penyusun menambahkan perhitungan kegiatan pengangkutan muatan steel billet ini mulai dari dermaga ke gudang milik pemilik barang yaitu di PT Krakatau Osaka Steel. Dalam kegiatan bongkar steel billet perusahaan trucking yang telah ditunjuk oleh pemilik barang untuk mengangkut muatan dari dermaga ke gudang PT Krakatau Osaka Steel telah menyediakan 20 truk pengangkut pada kegiatan bongkar steel billet di Pelabuhan Ciwandan Banten oleh PT Bintang Mustika Sakti selaku perusahaan bongkar muat.

Perhitungan kinerja truk pengangkut ketika cargo mulai dimuat kemudian pengiriman ke gudang consignee sampai kembali lagi ke pelabuhan adalah sebagai berikut :

1) Setiap truk yang dimuat membawa 30 pcs steel billet dan pada proses pemuatan membutuhkan waktu 6 menit.

2) Waktu yang dibutuhkan supir untuk mengencangkan lashing adalah 3 menit.

3) Jarak tempuh ke gudang consignee sejauh $17 \mathrm{~km}$ dengan kecepatan truk 50 
$\mathrm{km} / \mathrm{jam}$ maka waktu yang ditempuh dihitung dengan rumus :

$$
\mathrm{t}=\frac{S}{V}
$$

Keterangan :

$\mathrm{t}$ : waktu tempuh (jam, second)

$\mathrm{s}$ : jarak yang ditempuh $(\mathrm{m}, \mathrm{km})$

$\mathrm{v}:$ kecepatan $(\mathrm{km} / \mathrm{jam}, \mathrm{m} / \mathrm{s})$

$$
\mathrm{t}=\frac{17 \mathrm{~km}}{50 \mathrm{~km} / \mathrm{jam}}=34 \text { menit }
$$

Jadi waktu yang ditempuh dari pelabuhan ke gudang consignee dengan jarak $17 \mathrm{~km}$ dan kecepatan $50 \mathrm{~km} / \mathrm{jam}$ adalah 34 menit.

Hambatan-hambatan yang penyusun alami selama melaksanakan praktik dalam mengurusi pembongkaran steel billet bersama PT Bintang Mustika Sakti antara lain :

1) Faktor alam atau cuaca yang sering kali buruk, kemudian gelombang yang tinggi sehingga menghambat kegiatan pembongkaran di pelabuhan.

2) Banyaknya buruh TKBM yang kerap tidak menggunakan Alat Pelindung Diri (APD) membuat resiko terjadinya kecelakaan kerja menjadi tinggi.

3) Adanyakendala seperti waiting truck yang membuat pengerjaan pengangkutan muatan dari dermaga ke gudang menjadi terlambat.

\section{KESIMPULAN}

Dari pembahasan di atas, penyusun dapat menyimpulkan bahwa dalam prosedur pembongkaran steel billet oleh PT. Bintang Mustika Sakti di Pelabuhan CiwandanBanten adalah sebagai berikut :

1) Dalam pelaksanaannya, proses pembongkaran general cargo (steel billet) pada MV Harmony SW yang ditangani oleh PBM PT Bintang Mustika Sakti dapat berjalan dengan lancar dikarenakan adanya dokumen-dokumen pendukung yang dapat memperlancar proses perijinan pelaksanaan pembongkaran, persiapan personil dan persiapan peralatan mekanis dan nonmekanis yang memadai.

2) Kinerja peralatan bongkar steel billet yang dilaksanakan oleh PBM PT Bintang Mustika Sakti pada kapal MV Harmony SW di Pelabuhan CiwandanBanten sudah sangat baik. Kinerja perhitungan pengangkutan muatan dari dalam palka ke dermaga menggunakan ship's crane dapat dilakukan selama 5 menit dan dalam 1 jam mampu mengangkat 60 muatan. Waktu yang dibutuhkan untuk membongkar 4.823 pcs steel billet kurang lebih selama 81 jam, didukung pula dengan pemindahan muatan menggunakan forklift dari dermaga ke atas kapal dapat dilakukan dalam waktu 2 menit. Serta kendaraan truk pengangkut yang digunakan untuk mengangkut muatan dari dermaga ke gudang penumpukan dengan jarak tempuh $17 \mathrm{~km}$ dan kecepatan rata-rata 50 $\mathrm{km} / \mathrm{jam}$ dapat ditempuh dengan waktu 34 menit sehingga proses pengangkutan muatan dapat berjalan dengan baik.

\section{DAFTAR PUSTAKA}

Hutomo.M,S, 2020, Pelabuhan: Pengertian dan Fungsinya. https://indomaritim.id. Diakses Tanggal 20 januari 2021.

Mardalis, 2010, Metode Penelitian (Suatu Pendekatan Proposal), Edisi 1, Cetakan 12, Bumi Aksara, Jakarta

Muryaningsih, I, 2006, Pelaksanaan Bongkar Muat barang oleh PT. Dharma Lautan Nusantara di Pelabuhan Tanjung Emas Semarang Tinjauan Aspek Yuridis, Fakultas Ilmu Sosial. Universitas Negeri Semarang, Semarang.

Sugiyono, 2015, Memahami Penelitian Kombinasi (Mixed Method), Alfabeta, Bandung.

Suyono RP, 2007, Shipping: Pengangkutan Intermodal Ekspor Impor Melalui Laut, Edisi 4, Jakarta 